\title{
A Study on Jazz Vocal Variation Techniques -Focusing on Jazz Ballad Style Techniques-
}

\author{
Hyun-Jung Lee1)
}

\begin{abstract}
This study was conducted to provide musicians singing jazz ballads with a guideline of expressing variations so they can sing through diverse changes. To analyze a variety of vocal expression techniques of jazz ballads, songs that have been recorded predominantly for jazz vocal albums were selected. The analysis focuses on rhythmic variation and melodic variation techniques, from the perspective of rhythm, melody and harmony, which are basic components of music. In relation to rhythmic variation, polyrhythm, grouping, syncopation and lay-back expression techniques were analyzed, and in relation to melodic variation, disjunct motions, melodic variations during chord progression, scales, chromatic and line cliché were analyzed. In conclusion, rhythmic variations were characterized by groove changes, contrasting groove expressions through syncopation and lay-back, quarter-note triplets, accent expressions in syncopation and different rhythmic style expressions depending on tempo changes. Melodic variations were characterized by effects emphasized by disjunct motions and the relation with ranges, melodic variations with prominent chord features during chord progression, line cliche using interplay with musical instrument, patterned chromatic progression that adds ornament notes or scale expression methods in a wide range.
\end{abstract}

Keywords: Jazz Vocal, Jazz Ballad, Summertime, Variation, Rhythmic Variation, Melodic Variation

\section{Introduction}

\subsection{Research Objective}

Among jazz standard songs, ballad style has a slow tempo, so there is more timely and spatial leisure compared to other songs with a faster tempo; further, different variation techniques can be used. Therefore, this study aims to suggest variation methods for vocalists who sing jazz ballads, so that they can sing through different variations

\subsection{Research Method and Range}

Received(April 24, 2020), Review Result(1st: June 8, 2020, 2nd: July 27, 2020), Accepted(August 28, 2020)

1) (Professor) 06133 Dept. contemporary Music, Korea Nazarene Univ., 48, Wolbong-ro, Seobuk-gu, Cheonan-si, Chungcheongnam-do, Korea

email: jazzhj@kornu.ac.kr 
To study different expression techniques of jazz ballads, a piece of ballad music that was recorded predominantly in jazz vocal albums was selected. Accordingly, the vocal variation techniques used in each of the different versions were analyzed.

The expression techniques of vocals include rhythmic variation, melodic variation, articulation, and vibrato[1]. Among these, this study framed an approach from the rhythm melody and harmony-which are the basic elements that make up the music-and the research is centered on the techniques of rhythmic and melodic variation. Rhythmic variation analyzes the polyrhythm, grouping, syncopation, and lay-back expression techniques[2][3]. Melodic variation analyzes the disjunct motion, melodic variation, and scale followed by chord progression, chromatic, and line cliché expression techniques to obtain the results.

\section{Selection of the Song to Analyze}

\subsection{Selection Standard of the Song to Analyze}

To select the song to analyze, resources on the website Jazz Standard were used as a reference. This website has detailed information on the top 300 jazz standards and preserves the music composition data of the jazz standard[4]. For the genre and style classification, the 100 top songs-among the 1,000 jazz standard composition lists recorded most frequently in the Jazz Standard website-were extracted based on how they existed in standard music[5][6]. This is classified into five types: blues, swing, ballad, bebop, and Latin. When the top 100 songs were analyzed, there were 41 ballads, which amounted to a large proportion of the sample, and 6 out of the top 10 songs were ballads[7]. The titles of the classified ballad songs are "Body and Soul", "Summertime", "Round Midnight", "I Can't Get Started (with you)", "My Funny Valentine", and "Lover Man (Oh, Where Can You Be?)[8]". Out of these songs, "Summertime" was recorded the most, which is why it was chosen[9].

[Table 1] Selection of Song to Analyze

\begin{tabular}{|c|c|}
\hline Rank & Title \\
\hline 3 & "Summertime" \\
\hline 6 & "My Funny Valentine" \\
\hline 4 & "Round Midnight" \\
\hline 1 & "Body and Soul" \\
\hline 7 & "Lover man" \\
\hline 5 & "I Can't Get Started" \\
\hline
\end{tabular}


The version of the analyzed song is centered on the jazz standard that is predominant in jazz. For this, the time period was limited to between 1929 and 1940, as this period was the Jazz Age of jazz standard. Participants were selected according to which female jazz vocalists were active during this period[10][11]. For the recording version of "Summertime" there are seven musicians, including Billie Holiday, Carmen Mcrae, Ella Fitzgerald, Lena Horne, Mildred Bailey, Peggy Lee, and Sarah Vaughan. In addition to the version where recording information could not be found, there were 19 versions that were recorded by these artists. There were seven versions based on the initial recording or the first version released as an album for the classification, excluding the song that one person sang in different versions. In the classified version, four versions recorded by Billie Holiday, Ella Fitzgerald, Peggy Lee, and Sarah Vaughan, respectively, were derived, excluding the version where the rhythmic style overlaps or was recorded by focusing on the melody of the original song[12].

\section{Analysis and Derivation of the Variation Technique}

\subsection{Rhythmic Variation}

\subsubsection{Rhythmic Variation by Billie Holiday}

The first vocal expression technique is a rhythmic variation. This version is the rhythmic variation by Billie Holiday, and it is the score from the incomplete bar until measure 3 . In the phrase, Billie Holiday used a syncopation technique where the first motive is expressed as a sixteenth note, and accurate timing of the syncopation creates tension. The lay-back technique is triplet in the second motive used on beat and creates a relaxation effect, and in one phrase, two motives are expressed as contrasting grooves. From the second pattern, the lay-back technique is continuously used regardless of the motive.

\subsubsection{Rhythmic Variation by Peggy Lee}

This version is the rhythmic variation by Peggy Lee, and it is the score of measure 4 of the intro until measure 3 of the head. The original song is made up of a quarter note, a whole note, and straight 8 beats. In the song, Peggy Lee grouped two notes among the triplets of the eighth note and continuously used the connected rhythm to express her rhythmic groove. 


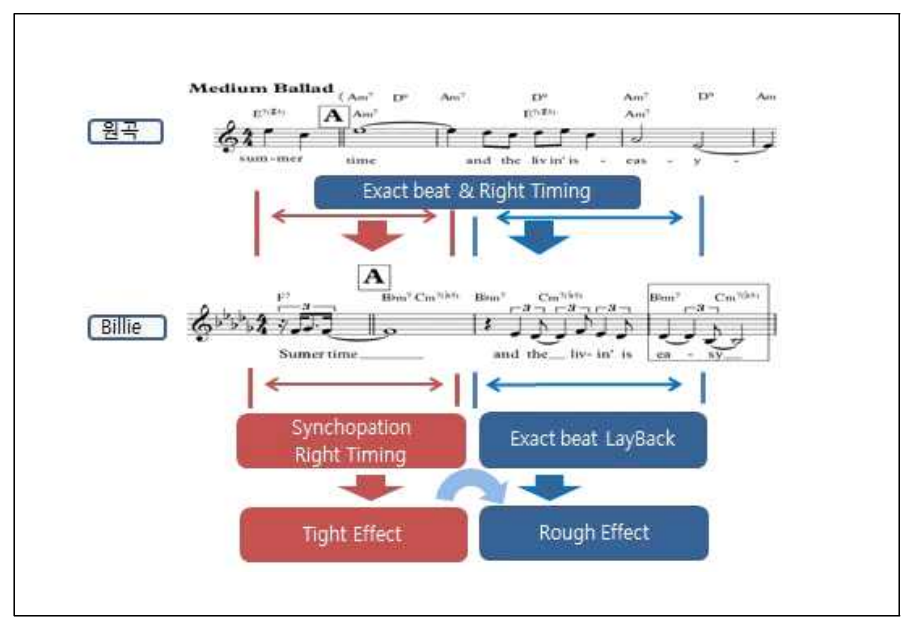

[Fig. 1] Rhythmic Variation Technique with the Application of Syncopation and Lay-back

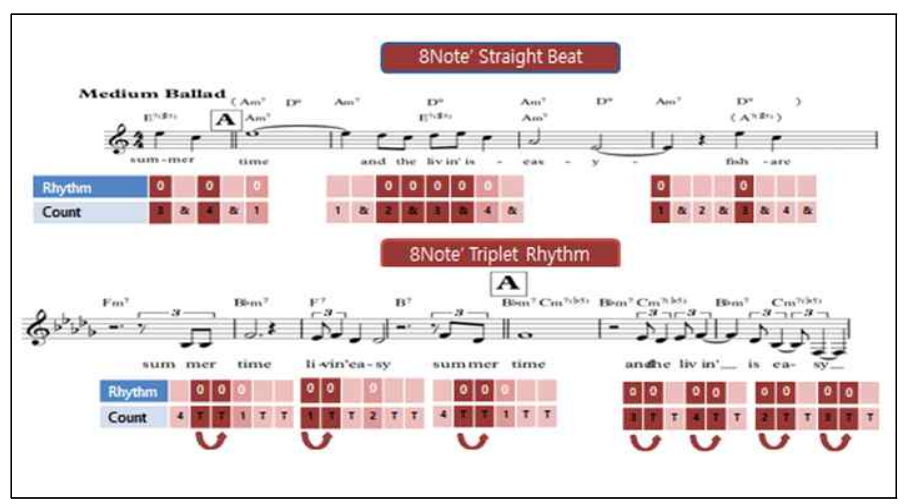

[Fig. 2] Rhythmic Variation Technique with the Application of Grouping

\subsubsection{Rhythmic Variation by Sarah Vaughan}

This version is the rhythmic variation of Sarah Vaughan. The first and second scores are from the incomplete bar until measure 3, and it has a unique form in the musical arrangement of musical instruments and the vocals. In the first phrase, the contrabass line powerfully expresses the eighth note straight beat theme, and it is performed in polyrhythm mixed with the swing beat of the vocals, so it has heterogeneity. The third and fourth scores are from measures 4 to 7, and it is the second phrase. Both the musical instrument and vocals perform with swing rhythm and express homogeneity. As evident in the score, in the case of syncopation, it is expressed with the eighth note on all motives, so it is used in various ways. 


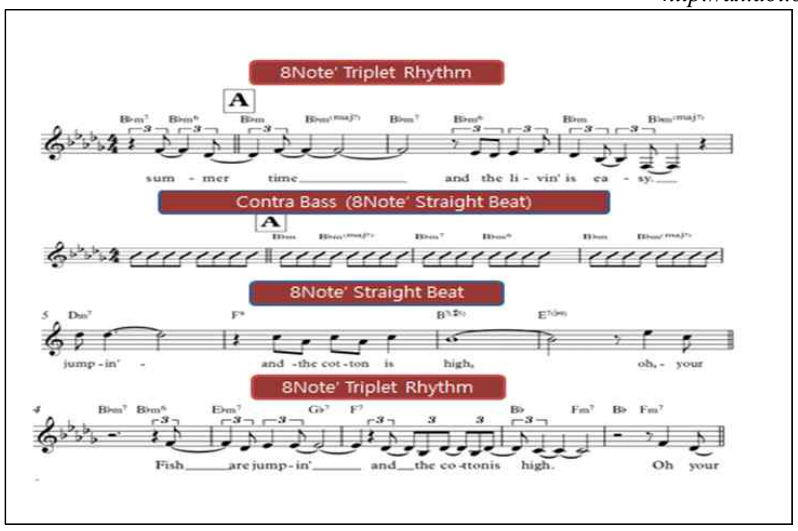

[Fig. 3] Rhythmic Variation Technique with the Application of Polyrhythm

\subsubsection{Rhythmic Variation by Ella Fitzgerald}

This version is the rhythmic variation by Ella Fitzgerald. The first is the score from the incomplete bar up to measure 4, and the second is the score from measure 34 up to measure 38. The two scores are the same section with part A of head and head out, and there is a large variation in the tempo with slow and fast tempo. In the slow tempo, there is a sixteenth note straight beat, and in the fast tempo, there is an eighth note swing beat, so different rhythm styles are expressed. In addition, the syncopation technique was used where it was pulled up to the eighth note to give it an accent. The third score ranges from 51 to 53, and it expressed a polyrhythm of quarter note triplets; therefore, it can be recognized that different techniques of rhythmic variation were used.

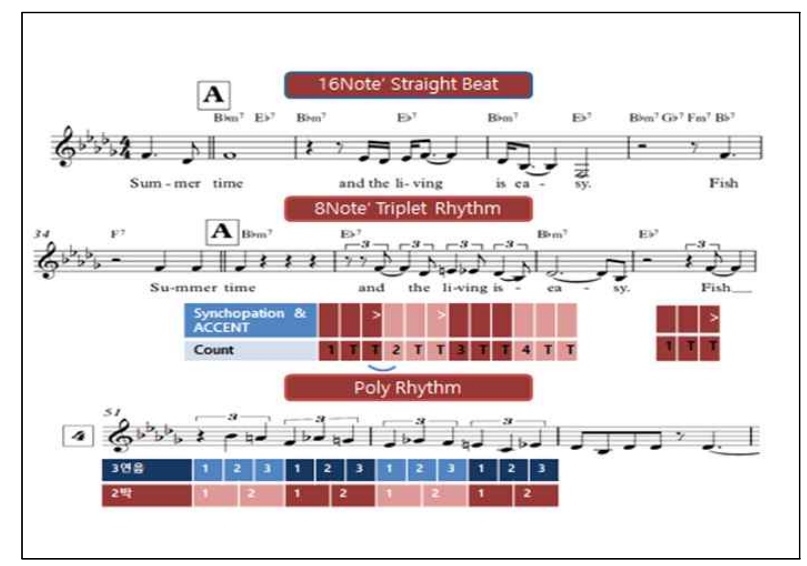

[Fig. 4] Rhythmic Variation Technique with the Application of 16note' Straight Beat and 8note' Swing Beat 


\subsection{Melodic Variation}

[Table 2] presents the key, range, and song format in the four versions of the analyzed song; the original song of "Summertime" is a thirty-two bar form song that begins with an incomplete bar. The key is all the same, but there are noticeable differences in the range.

[Table 2] 4 Versions of "Summertime" the Song to Analyze

\begin{tabular}{|c|c|c|c|}
\hline Vocal & Key & Range & Song Form \\
\hline Billie Holiday & $\mathrm{Bbm}$ & A3-G4 & Intro-Head A B-Solo-Head OutB \\
\hline Peggy Lee & $\mathrm{Bbm}$ & F3-B b 4 & Intro-Head $\mathrm{A}] \mathrm{B}$-Head OutB-Outro \\
\hline Sarah Vaughan & $\mathrm{B} b \mathrm{~m}$ & F3-C5 & $\begin{array}{c}\text { Intro-Head A-Interlude-Head B-Head } \\
\text { Out B-Outro }\end{array}$ \\
\hline Ella Fitzgerald & $\mathrm{B} b \mathrm{~m}$ & F3-D5 & $\begin{array}{c}\text { Intro-Head } \mathrm{A} \mid \mathrm{B} \text {-Interlude- } \\
\text { Head Out } \mathrm{A} \text { B-Narration\&Solo-Outro }\end{array}$ \\
\hline
\end{tabular}

\subsubsection{Melodic Variation by Billie Holiday}

The second vocal expression technique is melodic variation. This version is the melodic variation by Billie Holiday. For the note of "easy" the lyrics in measure 3, chord tone was used to bring a melodic variation and narrow down the range. In addition, in a similar section where the phrase finishes, a variation is provided with the same note, so a monotonous melodic variation is presented within a narrow range.

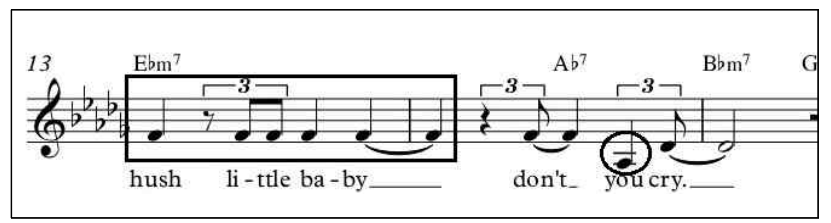

[Fig. 5] Melodic Variation Technique with the Application of Disjunct Motions

[Fig. 5] shows the score for measures 13 to 15 . It is the section to finish off $\mathrm{A}$ section, and the chord progression is reharmonized with $\mid \mathrm{W} \mathrm{m} 7$ and $\mathrm{V} \| b 7$. Billie Holiday tried to bring a melodic variation based on the chord progression, so she created tension and made it continue for the notes of "hush little baby" with the same tension notes. That was why she used the root, which was the lowest note for the note of the lyric "you" and during the major sixth disjunct motion, she gave it a melodic variation as the solution function for stability. Simultaneously, the root was used to create a close relationship with the range. 


\subsubsection{Melodic Variation by Peggy Lee}

Peggy Lee's version is mainly made of melodies centered on the original song and in specific lyrics like "summertime" and "singin" Only two notes-B b and F-were used, so there was a repetitive disjunct motion perfect fourth or fifth to give it an effect of emphasizing the lyrics.

\subsubsection{Melodic Variation by Sarah Vaughan}

Line cliché ascends or descends by half step intervals of tones when it progresses with one chord. Generally, it starts on the fifth note, sixth note, seventh note, and the root and line cliche that begins in the ninth note is very rare. This version is the melodic variation by Sarah Vaughan, and it is the score of part B that starts the head out. The chord progression was reharmonized with $|b \mathrm{~m}-| b \mathrm{mM}-|b \mathrm{~m} 7-| b \mathrm{~m} 6$ in the chorus of the song, and the orchestra continuously performed the line cliché. Sarah Vaughan uses line cliché twice in head out. In the first phrase, first of all, it was in an upward motion of perfect fourth interval for disjunct motion and in the chord progression section that was the same as the line cliché performed by the musical instrument. It starts with the root and then leads to a descending chromatic motion and creates a melodic variation. Here, line cliché is used simultaneously as the disjunct motion, so it creates an effect of making the melody stand out and shows interplay with the musical instrument. The second line cliché uses a rare case of line cliché, with an ascending disjunct motion in the perfect fifth interval, and then starts from the ninth note and leads to a descending chromatic motion and creates a melodic variation.

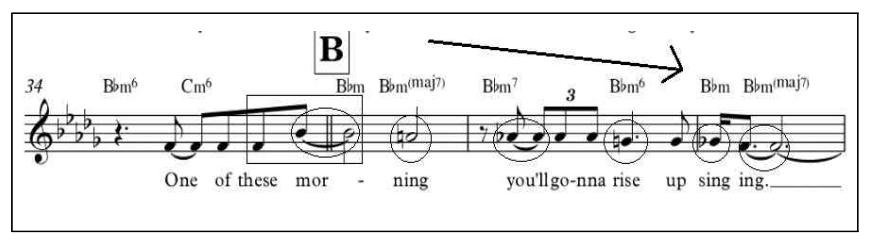

[Fig. 6] Melodic Variation Technique with the Application of Line Cliché

\subsubsection{Melodic Variation by Ella Fitzgerald}

The melodic variation by Ella Fitzgerald is the score from meters 14 and 30. Ella Fitzgerald uses Locrian and Mixolydian b9b13 mode in the minor IIm7(b5)-V7(b9b13) chord progression, which is the last section during the slow tempo and expresses fancy melody through the sixteenth note melisma expression technique. The disjunct motion mostly uses ascending and descending motions variedly in an interval of one octave above the fourth in 
the intro of the phrase after section $B$ changes.

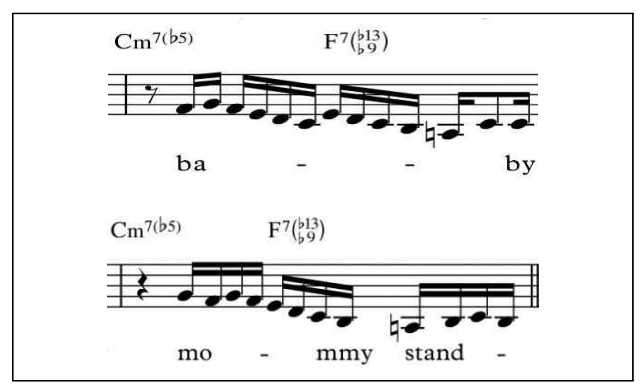

[Fig. 7] Melodic Variation Technique with the Application of Locrian and Mixolydian b 9, b13 Mode

The first is the score for meters 58 to 60 , and it starts in F up to the F note an octave higher, so it uses a wide range and ascends from $\mathrm{B} b$ pentatonic scale and also incorporates anticipation in the middle to create a pattern. In the second score, a quarter-note triplet polyrhythm was used with a chromatic descending progression starting with $\mathrm{B} b$, and what stood out was how the notes of the scale for the chord were used decorativelysimultaneously, a sequence was made to create an orderly pattern.

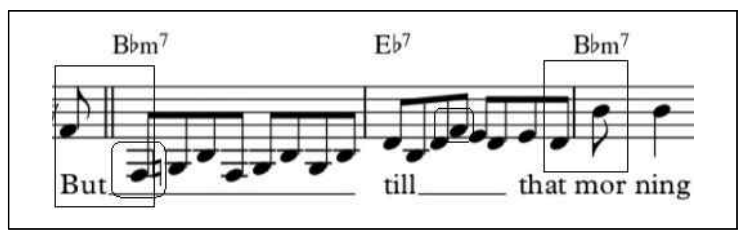

[Fig. 8] Melodic Variation Technique with the Application of B b Pentatonic Scale

\section{Conclusion}

This study is aimed to suggest variation methods to vocalists who sing jazz ballads, so that they can sing through different variations. To suggest various vocal expression techniques of a jazz ballad, "Summertime" which is a piece of ballad music that was recorded predominantly in jazz vocal albums, was selected, and different variation techniques applied in each of the four different versions of "Summertime" by Billie Holiday, Peggy Lee, Sarah Vaughan, and Ella Fitzgerald were analyzed. The vocal expression techniques are approached from the basic elements that make up the music, which are the rhythm, melody, and harmony. The rhythmic variation and melodic variation methods were analyzed to gain the techniques, and each 
musician showed distinct variation characteristics.

In the rhythmic variation, Billie Holiday used the syncopation technique in the first motive, which is expressed as a sixteenth note in the accurate timing to express tense groove. In the second motive, the lay-back technique was used to express a relaxed groove and formed a contrastive rhythmic groove. Peggy Lee used a rhythm that grouped 2 notes among the triplet of the eighth note and expressed her unique rhythmic groove. Sarah Vaughan showed a unique aspect in the musical arrangement with the musical instruments and vocals, and while the first phrase carries heterogeneity with polyrhythm mixed with the straight beats of the contrabass and the swing beat of the vocal, the second phrase had the musical instruments and vocals all performing with swing rhythm and expressed grooves with homogeneity. Finally, Ella Fitzgerald completed her rhythmic variation through the syncopation technique of pulling up to the eighth note to express the accent and also the technique of applying a polyrhythm of quarter note triplets.

In the melodic variation, Billie Holiday used chord tone for the expression in a narrow range to bring a melodic variation, and for the melodic variation of the $\mid \mathrm{V} m 7-\mathrm{V} \| b 7$ chord progression-which is the last part of the section-and the tension was sustained with the same tension note. Subsequently, major sixth disjunct motion was progressed with the root-the lowest range-so, this provided a solution function and also expressed the characteristic of having a close relationship with the range simultaneously. Peggy Lee used specific notes B b and $\mathrm{F}$ for the same lyrics and progressed a repetitive disjunct motion in perfect fourth or perfect fifth and gave the effect of emphasizing the lyrics. Sarah Vaughan used an interplay technique with a musical instrument and it was ascended to the perfect fourth or perfect fifth interval for disjunct motion. The line cliché performed by the musical instruments part was applied in the same chord progression to give it a melodic variation, and by using the disjunct motion and line cliché simultaneously, it was effective for making the melody stand out. Ella Fitzgerald used Locrian and Mixolydian b9b13 mode in the chord progression of minor $\| \mathrm{m} 7$ (b5)- $47(b 9 b 13)$, which is the last part of the section during the slow tempo and expressed fancy melody through the melisma expression technique. The disjunct motion used ascending and descending motions variedly in an interval of one octave above the fourth. A pattern was created by using a wide range by starting from $\mathrm{F}$ up to the $\mathrm{F}$ note an octave higher and ascending to $\mathrm{B} b$ pentatonic scale and using anticipation in the middle. In addition, it stood out that during the chromatic descending progression, which starts out with $\mathrm{B} b$, the notes of the scale in the chord were used decoratively in between, and an orderly pattern was created by organizing a sequence. 
Consequently, each musician expressed different jazz ballad grooves and lyrics through rhythmic variation and melodic variation. If the vocals that intend to sing in the jazz ballad style use these expression techniques appropriately, it is anticipated that they can sing in different variations.

\section{References}

[1] J Tolson, Jazz Style and Articulation: How to Get Your Band or Choir to Swing, Music Educators Journal, (2012), Vol.99, No.1, pp.80-86.

[2] C. K. Lee, S. S. Lee, K-POP Contents Development through the Fusion of Gutgeori Jangdan and Rumba Clave Rhythm, Asia-pacific Journal of Multimedia Services Convergent with Art, Humanities, and Sociology, (2017), Vol.7, No.5, pp.713-720.

[3] C. K. Lee, S. S. Lee, A popular music rhythm content development through a convergence of Korean folk music and Latin music, Asia-Pacific Journal of Advanced Research in Music, Art, Culture and Literature, (2016), Vol.1, No.1, pp:17-22.

[4] http://www.jazzstandards.com/compositions/index.htm, May 1 (2020)

[5] Wilbur R. Baker, Jr., An analysis of vocal jazz repertoire by three selected publishing companies, Sage Journals, (2011), Vol.30, No.1, pp.54-63.

[6] D. E. Brooks, Vocal jazz repertoire from 1920-1960: A selection of unpublished repertoire by the Mills Brothers, the Boswell Sisters, and the Hi -Lo's for use in classical choral programming, University of Southern California, Doctoral Dissertation, (2009)

[7] H. J. Lee, S. S. Lee, A Study on the Repertoire Arrangement Characteristic of Jazz Vocal, 2018 Spring Comprehensive Academic Conference of The Korea Contents Association, (2018), May 11 12; Mokpo, Korea

[8] Timothy C. Buchholz, Analysis and Categorization of Selected Musical Elements within Forty-three Solo Jazz Vocal "Standards" with Pedagogical Application to Repertoire Selection and the Teaching of Jazz Concepts in the Jazz Voice Lesson, University of Miami, Doctoral Dissertation, (2010)

[9] Ted Gioia, The Jazz Standards: A Guide to the Repertoire, UK: Oxford University Press, (2012)

[10] Wendy Hargreaves, Profiling the jazz singer, British Journal of Music Education, (2013), Vol.30, No.3, pp.383-396.

[11] Scott Yanow, The Jazz Singers: The Ultimate Guide, USA: Backbeat BOOKS, (2008)

[12] H. J. Lee, S. S. Lee, A Study on the Characteristics of Louis Armstrong's Scat, Asia-Pacific Journal of Advanced Research in Music, Art, Culture and Literature, (2016), Vol.1, No.1, pp.29-34. 